\title{
Gene Transfer into Hepatocytes Mediated by Helper Virus-Free HSVIAAV Hybrid Vectors
}

\author{
Cornel Fraefel, ${ }^{1,2}$ David R. Jacoby, ${ }^{1}$ Christopher Lage, ${ }^{2}$ \\ Harold Hilderbrand, ${ }^{2}$ Janice Y. Chou, ${ }^{4}$ Fred W. Alt, ${ }^{3}$ \\ Xandra O. Breakefield, ${ }^{1}$ and Joseph A. Majzoub ${ }^{2}$ \\ ${ }^{1}$ Molecular Neurogenetics Unit, Massachusetts General Hospital, \\ Harvard Medical School, Charlestown, Massachusetts, U.S.A. \\ ${ }^{2}$ Division of Endocrinology, and ${ }^{3}$ Howard Hughes Medical Institute, \\ The Children's Hospital, Harvard Medical School, Boston, \\ Massachusetts, U.S.A. \\ ${ }^{4}$ Heritable Disorders Branch, National Institute of Child Health and \\ Human Development, NIH, Bethesda, Maryland, U.S.A.
}

\begin{abstract}
Background: Vectors based on herpes simplex virus type 1 (HSV-1) can efficiently transduce hepatocytes in the mouse liver, and vector genomes can persist for at least 2 months. However, $24 \mathrm{hr}$ after gene transfer, the number of cells that express the transgene decreases rapidly and no transduced cells are detectable after 7 days. In this study, we examined the capability of a helper virus-free HSV/AAV hybrid amplicon vector to extend transgene expression in hepatocytes in vivo.

Materials and Methods: HSV-1 amplicon or HSV/ AAV hybrid amplicon vectors that express reporter genes from different transcriptional regulatory sequences were packaged into HSV-1 virions using a helper virus-free packaging system. To determine relative transduction efficiencies, vector stocks were titered on four different cell lines, including hamster kidney (BHK21) and human lung (Hs913T) fibroblasts, and mouse (G6Pase-/-) and human (NPLC) hepatocytes. After in vivo injection of vector stocks into mouse liver, tissue sections were examined for reporter gene expression and cellular inflammatory response. Blood samples were collected to measure serum transaminase levels as a biochemical index of liver toxicity.
\end{abstract}

Address correspondence and reprint requests to Dr. Cornel Fraefel at his current address: Institute of Virology, University of Zurich, Winterthurerstrasse 266a, CH-8057 Zurich, Switzerland. Tel: (41) 1635 8701; Fax: (41) 1635 8911; Email: cornelf@vetvir.unizh.ch
Results: Expression of a reporter gene from liver-specific promoter sequences was consistently more effective in hepatic cells compared with fibroblasts, whereas the opposite was true when using an HSV-1 immediateearly promoter. Expression in hepatocytes in vivo was markedly longer from HSV/AAV hybrid vector compared with traditional HSV-1 amplicon vector: the number of transduced cells $(\sim 2 \%$ of all hepatocytes) remained stable over 7 days after injection of HSV/AAV hybrid vector, whereas no transduced cells were detected 7 days after gene transfer with standard HSV-1 amplicon vector. The rapid decline in reporter gene expression from standard amplicons was not solely caused by a B or T lymphocyte-mediated immune response, as it also occurred in RAG2- $/-$ mice. Hepatocyte toxicity and cellular inflammatory effects associated with HSV/ AAV hybrid vector-mediated gene transfer were minimal, and readministration of vector stock proved equally effective in naive mice and in animals that received a first vector dose 4 weeks earlier.

Conclusions: HSV/AAV hybrid amplicon vectors support gene expression in vivo for considerably longer than do traditional HSV-1 amplicon vectors. Moreover, expression from these vectors does not provoke an overt inflammatory or immune response, allowing efficacious expression following repeated in vivo dosing. These characteristics suggest that such vectors may hold future promise for hepatic gene replacement therapy. 


\section{INTRODUCTION}

Direct gene transfer into hepatocytes in vivo is highly desirable because the liver is the prime target of many metabolic disorders, infectious diseases, and cancers. Some metabolic disorders can be treated by periodic infusion of the deficient protein or by liver transplantation; however, all forms of current therapies have limitations. Since many of the inborn errors of metabolism, such as glycogen storage disease type la, familial hypercholesterolemia, familial hyperbilirubinemia (Crigler-Naijar syndrome), and hemophilia, are caused by monogenic defects, replacement of the defective gene in a subset of liver cells may be an effective treatment alternative.

Although nonviral delivery systems such as cationic liposomes can transfer genes into hepatocytes in vivo, vectors based on animal viruses are more effective because, as obligate parasites, they have evolved efficient strategies to enter host cells (1). Consequently, a number of vector systems, including those based on retrovirus, adenovirus, adeno-associated virus (AAV), and herpes simplex virus type 1 (HSV-1) have been developed. Retrovirus vectors have been extensively used as gene delivery vehicles because they can stably integrate into the genome of dividing cells; however, those vectors derived from Moloney murine leukemia virus (MoMLV) are ineffective for transferring genes directly into nondividing cells, such as hepatocytes in vivo (2-4). Adenovirus vectors have been demonstrated to infect hepatocytes in vivo (5-7), but they support only short-term gene expression and inefficient gene transfer and, moreover, induce cytotoxic effects and a vigorous immune response $(8-10)$. AAV is an ideal candidate for vector development because this virus can stably integrate into the human genome (preferentially into chromosome 19q13.3-qter) of dividing and nondividing cells while causing minimal cytopathic effects (11). AAV vectors are created by substituting a transgene cassette for the viral rep and cap genes, which are flanked by the AAV inverted terminal repeats (ITRs). After infection of cells, these vectors can either persist in an episomal form $(12,13)$ or integrate into the cellular genome (14-16). However, AAV vectormediated gene transfer into hepatocytes is inefficient $(17,18)$, and the limited transgene capacity of these vectors $(4.5 \mathrm{~kb})$ does not allow incorporation of the viral rep gene, which encodes proteins that have important functions in the specificity and efficiency of integration into the cellular genome $(19,20)$.

Both recombinant HSV-1 vectors and HSV-1 amplicons can efficiently infect many different cell types, including postmitotic neurons (21-23) and nondividing hepatocytes (24-26), but cytotoxicity and instability of gene expression have compromised the utility of conventional vector systems for gene transfer experiments (27). HSV-1 amplicons contain three types of genetic elements: (1) sequences from $E$. coli that allow plasmid propagation in bacteria; (2) the HSV-1 origin of DNA replication $\left(\right.$ ori $_{\mathrm{s}}$ ) and cleavage/ packaging signal (pac), which allow replication and packaging of the amplicon into HSV-1 virions in the presence of HSV-1 helper functions; and (3) a transcription unit bearing the gene(s) of interest (28). The cytotoxicity associated with HSV-1 amplicon vector-mediated gene transfer has been significantly reduced by the recent development of a helper virus-free packaging system, as it eliminates gene expression from helper virus conventionally used to package amplicons $(23,29,30)$. Although stability of gene expression is somewhat improved by the absence of helper virus alone (29), Johnston et al. (31) improved it further by developing an amplicon vector that combines the high infectibility and large transgene capacity of HSV-1 with the potential for episomal amplification and genome integration of AAV. This HSV/AAV hybrid vector is composed of (1) sequences from HSV-1 (ori ${ }_{\mathrm{s}}$ and pac), (2) a transgene cassette flanked by the AAV ITRs, and (3) outside of this cassette, the AAV rep gene that may mediate amplification and genomic integration of ITR-flanked sequences. The hybrid vector is packaged efficiently into HSV-1 virions by using either helper virus-dependent or helper virus-free packaging systems (31).

In this study, we evaluated the use of helper virus-free HSV-1 amplicon vectors for gene transfer into the liver. In particular, we examined the influence of different promoters on transduction efficiency in hepatocytes and fibroblasts, and the potential of HSV/AAV hybrid amplicon vectors to mediate extended transgene expression in mouse hepatocytes in vivo.

\section{MATERIALS AND METHODS}

\section{Cell Culture}

Baby hamster kidney BHK21 cells (ATCC), human lung Hs913T cells (ATCC) and human liver 


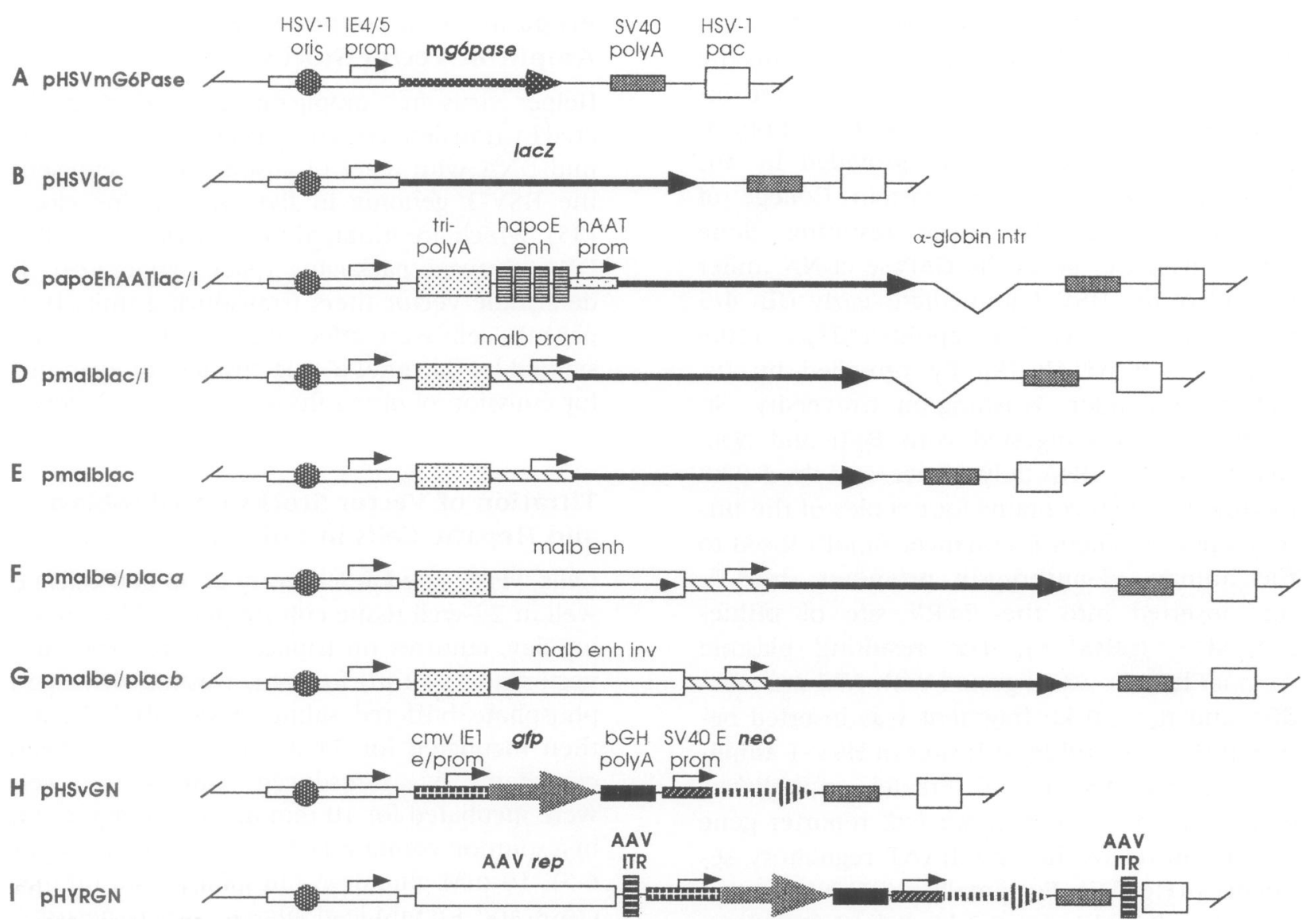

FIG. 1. Schematic diagram of HSV-1 amplicon and HSV/AAV hybrid vectors

(A) pHSVmG6Pase contains the mouse glucose-6-phosphatase cDNA (mG6Pase) under control of the HSV-1 immediate-early 4/5 promoter (IE 4/5 prom). (B-G) Amplicon vectors that contain the lac $Z$ reporter gene under transcriptional control of either (B) the IE 4/5 promoter (pHSVlac) or the liver-specific (C) human apolipoprotein E enhancer (hpaoE enh)/human $\alpha \mathrm{l}$-antitrypsin promoter (hAAT prom; papoEhAATlac/i), (D and E) the mouse albumin promoter (malb prom; pmalblac/i and pmalblac), or ( $\mathrm{F}$ and $\mathrm{G}$ ) the mouse albumin enhancer (malb enh, malb enh inv) and promoter (pmalbe/placa and pmalbe/placb). Two of the constructs (papoEhAATlac/i and pmalblac/i) contain the $\alpha$-globin intron (intr) downstream of the lac $Z$ open reading frame. (H) pHSvGN contains a transgene cassette consisting of the green fluorescent protein cDNA $(g f p)$ under control of the cytomegalovirus immediate-early l enhancer/promoter (cmv IEl e/prom) and the neomycin phosphotransferase cDNA (neo) under control of the SV40 early promoter (SV40 E prom). (I) HSV/AAV hybrid vector pHYRGN contains the adeno-associated virus (AAV) rep gene and the AAV inverted terminal repeats (ITR) that flank the same transgene cassette as in pHSvGN. All vectors contain the HSV-1 origin of DNA replication (HSV-l ori ${ }_{s}$ ) and the DNA cleavage/packaging signal (HSV-l pac) to support replication and packaging into HSV-1 virions in the presence of helper functions. Because the HSV-1 IE 4/5 promoter overlaps with ori $_{s}$ sequences, three copies of the SV40 polyadenylation signal (tri-polyA) were inserted upstream of the liver-specific promoter elements (41). The positions of the SV40 polyA signals that terminate transcription of the lac $Z$ and neo genes, and the bovine growth hormone (bGH) polyA signal that terminates transcription of the $g f p$ gene, are indicated.

NPLC cells (kindly provided by Dr. B. Knowles, Wistar Institute, Philadelphia, PA) were grown in Dulbecco's modified minimal essential medium (DMEM) supplemented with $10 \%$ fetal bovine serum (FBS) and $1 \%$ penicillin/streptomycin (P/S). Glucose-6-phosphatase (G6Pase)deficient mouse hepatocytes (G6Pase-/-) (32; J.Y. Chou, unpublished data) were cultured in
DMEM supplemented with $4 \%$ FBS, $0.1 \mu \mathrm{M}$ dexamethasone, and $1 \% \mathrm{P} / \mathrm{S}$. All cells were incubated at $37^{\circ} \mathrm{C}$ in a $5 \% \mathrm{CO}_{2}-95 \%$ air atmosphere.

\section{Construction of HSV-1 Amplicon Vectors}

Figure 1 illustrates the HSV-1 amplicon vectors used in this study. To construct pHSVmG6Pase 
(6.6 kb), plasmid pBmG6Pase was digested with $E c o$ RI, and the $1.9 \mathrm{~kb}$ fragment that contains the mouse G6Pase cDNA (33) was isolated and inserted into the EcoRI site of HSV-l amplicon plasmid pHSVPrPUC (kindly provided by Dr. Howard Federoff, Albert Einstein College of Medicine, Bronx, NY). The resulting clone (pHSVmG6Pase) bears the G6Pase cDNA under control of the HSV-1 immediate-early (IE) 4/5 promoter (Fig. 1A). For papoEhAATlac/i (10.6 $\mathrm{kb}$ ), plasmid p514B (kindly provided by Dr. Katherine Ponder, Washington University, St. Louis, MO) was digested with BglII and NotI, treated with T4 DNA polymerase, and the $1.0 \mathrm{~kb}$ fragment, which contains four copies of the human apolipoprotein E enhancer (apoE) fused to the human $\alpha 1$-antitrypsin promoter (hAAT), was inserted into the $E c o R V$ site of pBluescriptSK $+(\mathrm{pBsSK}+)$. The resulting plasmid (pBapoEhAAT) was digested with NotI and Hin$\mathrm{dIII}$, and the $1.0 \mathrm{~kb}$ fragment was inserted between the NotI and HindIII sites of HSV-1 amplicon plasmid pNSElac/i (C. Fraefel, unpublished data). This places the E. coli lacZ reporter gene under control of the apoEhAAT regulatory sequences (Fig. 1C). For pmalblac/i (10.4 kb) and pmalblac $(9.7 \mathrm{~kb})$, the $0.8 \mathrm{~kb}$ BamHI-BglII fragment from plasmid pl45 (kindly provided by Dr. Katherine Ponder) which contains the mouse albumin promoter (34) was inserted into the BamHI site of pBsSK + . The resulting clone (pBmalb) was digested with NotI and HindIII, and the $0.8 \mathrm{~kb}$ fragment was inserted between the NotI and HindIII sites of either pNSElac/i or pNSElac (C. Fraefel, unpublished data), generating pmalblac/i and pmalblac, respectively. In both amplicons, the lac $Z$ gene is under control of the mouse albumin promoter, but in contrast to pmalblac, pmalblac/i contains (similar to papoEhAAT) the $\alpha$-globin intron downstream of the lacZ open reading frame (Fig. 1D, E). To construct pmalbe/placa (11.7 kb) and pmalbe/placb (11.7 kb), plasmid pBacalb (kindly provided by Dr. Frederick Boyce, MGH, Charlestown, MA) was digested with BamHI, blunt end repaired with T4 DNA polymerase, and the $2 \mathrm{~kb}$ fragment containing the mouse albumin enhancer (34) was inserted into the blunt end-repaired (T4 DNA polymerase) NotI site of pmalblac (see above). Two clones with the enhancer sequences in opposite orientations were isolated and designated pmalbe/placa and pmalbe/plac $b$ (Fig. IF, G).

\section{Preparation of Helper Virus-Free HSV-1 Amplicon Vector Stocks}

Helper virus-free amplicon stocks were generated by transient cotransfection of amplicon plasmid DNA with a set of cosmids that represents the HSV-1 genome in five overlapping clones (35), which are mutated to inactivate the HSV-1 DNA cleavage/packaging (pac) signals (29). To determine vector titers (transducing units [t.u.] per $\mathrm{ml}$ ), cells were infected and $24 \mathrm{hr}$ later either stained for bacterial $\beta$-galactosidase or examined for emission of green fluorescence (see below).

\section{Titration of Vector Stocks on Fibroblast and Hepatic Cells in Culture}

Cells were plated at a density of 50,000 cells per well in 24-well tissue culture plates. The following day, cultures (in triplicate) were exposed to vector stocks $(2 \mu \mathrm{l})$ for $4 \mathrm{hr}$, washed twice with phosphate buffered saline (PBS; pH 7.4), and then incubated for $24 \mathrm{hr}$ at $37^{\circ} \mathrm{C}$. For G6Pase cytochemistry, transduced G6Pase-/- cells were incubated for $10 \mathrm{~min}$ at room temperature in a solution containing $40 \mathrm{mM}$ Tris-maleate $(\mathrm{pH}$ 6.5), $10 \mathrm{mM}$ glucose-6-phosphate, $300 \mathrm{mM}$ sucrose, and 3.6 mM lead nitrate. After exposure to $2 \%$ ammonium sulfide, the trapped lead phosphate was visualized as the colored lead sulfide (32). For $\beta$-galactosidase cytochemistry, transduced cells were fixed for 20 min with $4 \%$ paraformaldehyde in PBS, washed three times with PBS, and stained with 5-bromo-4-chloro-3-indolyl- $\beta$-D-galactopyranoside $(\mathrm{X}-\mathrm{Gal})$ at $37^{\circ} \mathrm{C}$. After $6 \mathrm{hr}$, the cultures were washed twice with $\mathrm{PBS}$, and $\beta$-galactosidase-positive cells were counted under a magnification of $\times 10$.

\section{Gene Transfer into Hepatocytes In Vivo}

Animal studies were performed in accordance with guidelines issued by the Children's Hospital Animal Care and Use Committee. Normal mice (strain C57BL/6, 9-12 weeks; Charles River Laboratories, Wilmington, MA, and Jackson Laboratories, Bar Harbor, ME) or immunodeficient mice (RAG2-/-, 10 weeks; 36) were anesthetized by intraperitoneal injection of $0.15 \mathrm{ml}$ of a solution consisting of $20 \%$ ketamine- $\mathrm{HCl}$ (Ketalar, $100 \mathrm{mg} / \mathrm{ml}$; Parke-Davis, Morris Plains, NJ), $20 \%$ xylazine (Rompun, $20 \mathrm{mg} / \mathrm{ml}$; Miles Inc., Shawnee Mission, KS), and $60 \%$ sodium chloride $(0.9 \%$; Abbott Laboratories, North Chicago, IL). The abdomen was opened through a midline 

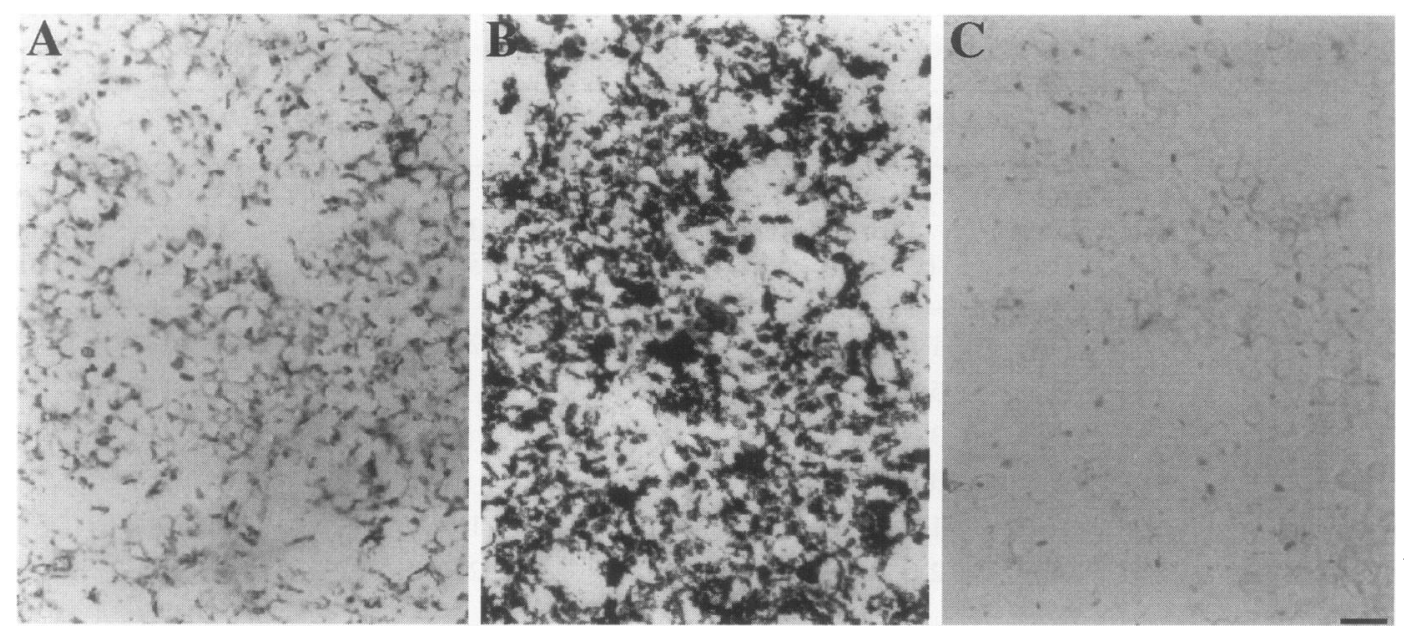

FIG. 2. HSV-1 amplicon vector-mediated expression of glucose-6-phosphatase in cultured hepatocytes from G6Pase deficient mice

pHSVmG6Pase and pHSVlac were packaged into HSV-1 virions by using the helper virus-free system. Glucose-6phosphatase-deficient mouse hepatocytes (G6Pase-/-) in culture were infected with either (A) $10 \mu \mathrm{l}$ or (B) $50 \mu \mathrm{l}$ of pHSVmG6Pase or (C) $10 \mu \mathrm{l}$ of pHSVlac stocks, and $24 \mathrm{hr}$ later, stained for G6Pase enzyme activity. Scale bar, $40 \mu \mathrm{m}$.

incision, and $100 \mu$ l vector stock was either injected directly into parenchyma of the left liver lobe or infused into the portal vein by using a 30 gauge needle. Blood samples ( 3 animals per group) were collected periodically and assayed for serum transaminase (ALT) levels and total bilirubin by colorimetric methodology. Following anesthesia and transcardial perfusion with PBS $/ 4 \%$ paraformaldehyde, liver, lung and kidney (two to three animals per group) were collected at various time points after gene transfer. Organs were postfixed in $4 \%$ paraformaldehyde in PBS for $4 \mathrm{hr}$, cryoprotected for 2 days with $30 \%$ sucrose in PBS, and cut in $20-\mu \mathrm{m}$ cryostat sections. Two out of every ten liver sections, and one out of every 20 kidney or lung sections were mounted on glass slides. Tissue was stained with either X-Gal or hematoxylin and eosin (HEE) and examined at a magnification of $\times 10$ and $\times 20$. For fluorescent detection of $g f p$-expressing cells, the sections were coverslipped using Aqua Poly/Mount medium (Polysciences Inc., Warrington, PA) and examined under a fluorescence microscope (Zeiss IM35; Carl Zeiss, Inc., Thomwood, NY).

\section{RESULTS}

\section{HSV-1 Amplicon Vector-Mediated Expression of Glucose-6-Phosphatase in Cultured Mouse Hepatocytes}

Glycogen storage disease type la (GSD la) is an autosomal recessive disorder caused by a defi- ciency in glucose-6-phosphatase (G6Pase) in the liver $(32,33,37,38)$. To determine whether genetic replacement could correct the defect in cultured hepatocytes derived from mice with a targeted deletion of the G6Pase gene (32), we constructed HSV-1 amplicon vector pHSVmG6Pase (Fig. 1A). G6Pase-1- hepatocytes were infected with helper virus-free stocks of either pHSVmG6Pase or, as a control, pHSVlac (39; Fig. 1B). Twentyfour hours later, G6Pase enzyme activity was clearly detected in pHSVmG6Pase-transduced cultures, but large volumes of vector stocks were required (Fig. 2). The method used to visualize G6Pase enzyme activity disrupts the cell monolayer and forms a diffuse lead precipitate that does not allow determination of vector titer. However, the titers of stocks of amplicon vector pHSVlac (which expresses the E. coli lacZ gene from the HSV-1 immediate-early (IE) 4/5 promoter) obtained on infection of G6Pase - / - cells was much lower compared with the titers obtained on BHK21 cells (see Table 1 and Fig. $3 C$ ). This suggested that the G6Pase-1- cells were less susceptible to HSV-1 infection than the BHK21 cells, and/or that the HSV-1 IE 4/5 promoter, which controls the expression of the transgenes in pHSVmG6Pase and pHSVlac, was less active in G6Pase-1- cells than in BHK21 cells. To explore the influence of the promoter, we compared the titers and transduction efficiencies seen between different cell lines on infection with HSV-1 amplicon vectors that express the $E$. coli lacZ gene from either the HSV-1 IE4/5 pro- 
TABLE 1. Transduction efficiencies of HSV-1 amplicon vectors in different cell lines

\begin{tabular}{|c|c|c|c|c|c|c|}
\hline \multirow[b]{2}{*}{ Vector } & \multicolumn{3}{|c|}{ BHK21 } & \multicolumn{3}{|c|}{ Hs913T } \\
\hline & $\begin{array}{c}\beta \text {-galactosidase- } \\
\text { positive cells }^{a}\end{array}$ & $\begin{array}{c}\text { Titer }^{b} \\
\text { (t.u. } / \mathrm{ml})\end{array}$ & $\begin{array}{c}\text { Relative } \\
\text { transduction } \\
\text { efficiency }\end{array}$ & $\begin{array}{l}\beta \text {-galactosidase- } \\
\text { positive cells }\end{array}$ & $\begin{array}{c}\text { Titer } \\
\text { (t.u./ml) }\end{array}$ & $\begin{array}{c}\text { Relative } \\
\text { transduction } \\
\text { efficiency }\end{array}$ \\
\hline pHSVlac & $2869 \pm 63$ & $1.4 \times 10^{6}$ & 1.00 & $3744 \pm 121$ & $1.9 \times 10^{6}$ & 1.30 \\
\hline papoEhAATlac/i & $993 \pm 26$ & $5.0 \times 10^{5}$ & 1.00 & $11 \pm 2$ & $5.5 \times 10^{3}$ & 0.01 \\
\hline pmalblac/i & $583 \pm 35$ & $3.9 \times 10^{5}$ & 1.00 & $16 \pm 7$ & $8.0 \times 10^{3}$ & 0.03 \\
\hline pmalblac & $669 \pm 9$ & $3.3 \times 10^{5}$ & 1.00 & $16 \pm 7$ & $8.0 \times 10^{3}$ & 0.02 \\
\hline pmalbe/placa & $3658 \pm 220$ & $1.8 \times 10^{6}$ & 1.00 & $191 \pm 69$ & $9.5 \times 10^{4}$ & 0.05 \\
\hline pmalbe/plac $b$ & $4051 \pm 93$ & $2.0 \times 10^{6}$ & 1.00 & $265 \pm 81$ & $1.3 \times 10^{5}$ & 0.07 \\
\hline
\end{tabular}

moter, the human apolipoprotein E enhancer/ $\alpha \mathrm{l}$-antitrypsin promoter (apoEhAAT), or from mouse albumin promoter (malb) with or without enhancer sequences (malbe/p). Both the apoEhAAT and the malb transcriptional regulatory sequences have previously been shown to confer liver-specific transgene expression from retroviral and adenoviral vectors, respectively $(4,40)$.

\section{Transduction Efficiency of HSV-1 Amplicon Vectors Is Influenced by the Promoter}

The HSV-1 amplicon vectors used in this experiment are illustrated in Figure 1 . The vectors were packaged into HSV-1 particles by using the helper virus-free packaging system. Each vector preparation was titered simultaneously on four different cell lines, including hamster kidney (BHK21) and human lung (Hs913T) fibroblasts, and mouse (G6Pase-l-) and human (NPLC) hepatocytes, as described in Materials and Methods. This assay detects cells that synthesize sufficient $\beta$-galactosidase to enable histochemical detection by light microscopy and does not distinguish between lightly and heavily stained cells. The relative transduction efficiency of each of the vectors on the different cell lines was determined by dividing the average number of $\beta$-galactosidase-positive Hs913T, NPLC, or G6Pase $-1-$ cells by the average number of $\beta$ - galactosidase-positive BHK21 cells, which served as a standard (relative transduction efficiency $=$ 1). Table 1 and Figure 3 show that pHSVlac (IE $4 / 5$ promoter) transduced hepatic cells with a much lower efficiency than kidney or lung fibroblasts $(\sim 10$-fold $)$. In contrast, those vectors which contained liver-specific promoter sequences were consistently more effective in transducing hepatic cells than lung (Hs913T) fibroblasts $(\sim 10-$ to 100 -fold), and equally or slightly less (2-fold) effective in transducing hepatic cells than kidney (BHK21) fibroblasts. The presence (pmalblac/i) or absence (pmalblac) of the $\alpha$-globin intron, as well as the orientation of the albumin enhancer (pmalbe/placa and pmalbe/placb) had no apparent effect on the relative transduction efficiencies on the different cell lines. This experiment was repeated with at least two different preparations of each vector and consistently showed comparable relative transduction efficiencies. Moreover, the absolute transduction efficiencies (number of $\beta$-galactosidase-positive cells) on the different cells correlated with the amount of vector inoculum applied, whereas the relative transduction efficiencies remained virtually constant (not shown).

\section{Gene Transfer into Hepatocytes In Vivo}

Previous reports demonstrated that HSV-1-based vectors, both recombinant viruses and ampli- 
TABLE 1. Continued

\begin{tabular}{|c|c|c|c|c|c|}
\hline \multicolumn{3}{|c|}{ G6Pase-I- } & \multicolumn{3}{|c|}{ NPLC } \\
\hline $\begin{array}{l}\beta \text {-galactosidase- } \\
\text { positive cells }\end{array}$ & $\begin{array}{c}\text { Titer } \\
\text { (t.u./ml) }\end{array}$ & $\begin{array}{c}\text { Relative } \\
\text { transduction } \\
\text { efficiency }\end{array}$ & $\begin{array}{l}\beta \text {-galactosidase- } \\
\text { positive cells }\end{array}$ & $\begin{array}{c}\text { Titer } \\
(\mathbf{t} . \mathbf{u} . / \mathbf{m l})\end{array}$ & $\begin{array}{c}\text { Relative } \\
\text { transduction } \\
\text { efficiency }\end{array}$ \\
\hline $487 \pm 36$ & $2.4 \times 10^{5}$ & 0.17 & $264 \pm 11$ & $1.3 \times 10^{5}$ & 0.09 \\
\hline $245 \pm 16$ & $1.2 \times 10^{5}$ & 0.25 & $1128 \pm 71$ & $5.6 \times 10^{5}$ & 1.14 \\
\hline $391 \pm 42$ & $1.9 \times 10^{5}$ & 0.67 & $749 \pm 21$ & $3.7 \times 10^{5}$ & 1.28 \\
\hline $367 \pm 57$ & $1.8 \times 10^{5}$ & 0.55 & $733 \pm 15$ & $3.7 \times 10^{5}$ & 1.15 \\
\hline $2296 \pm 36$ & $1.1 \times 10^{6}$ & 0.63 & $1840 \pm 145$ & $9.2 \times 10^{5}$ & 0.50 \\
\hline $2500 \pm 45$ & $1.2 \times 10^{6}$ & 0.62 & $2283 \pm 56$ & $1.1 \times 10^{6}$ & 0.56 \\
\hline
\end{tabular}

Cells (BHK21, Hs913T, G6Pase-/-, NPLC) were infected with $2 \mu$ l of vector stock and stained with X-Gal as described in the text and Materials and Methods.

${ }^{a}$ Numbers represent the mean $\pm \mathrm{SD}(n=3)$.

${ }^{b}$ Titers (t.u./ml; transducing units per $\mathrm{ml}$ ) $=$ mean number of $\beta$-galactosidase-positive cells $\times 500$.

cons, can efficiently transduce hepatocytes in vivo (24-26). However, in these studies, transgene expression decreased rapidly $24 \mathrm{hr}$ after gene transfer and no transduced cells were detected at 7 days after infection, although vector genomes could be shown to persist efficiently for at least 2 months (24).

We hypothesized that the helper virus-free amplicon vector system combined with the use of liver-specific transcriptional regulatory sequences may support long-term gene expression. To investigate this possibility, $5 \times 10^{5}$ transducing units (t.u.; as determined on BHK2 1 cells) of papoEhAATlac/i or pmalbe/placa were injected either intraportally or directly into the left liver lobe. At 1 day after gene transfer, $\beta$-galactosidase positive cells were detected in all animals with approximately $0.1 \%$ of all hepatocytes being transduced. Interestingly, the $\beta$-galactosidasepositive cells were equally distributed in the entire liver, independent of the infection route. At 7 days following gene transfer, however, no $\beta$ galactosidase-positive cells were observed in any animal examined (not shown). To assess whether transgene expression from an HSV-1based vector can be extended in immunodeficient animals, six RAG2- $-1-$ mice (36) were injected with helper virus-free stocks of pHSvGN, which expresses the green fluorescent protein cDNA $(g f p)$ from the cytomegalovirus ( $\mathrm{cmv}$ ) IEl enhancer/promoter (Fig. 1H). The titer of this vector was $\sim 40$-fold higher than those of the
papoEhAATlac/i or pmalbe/placa stocks used in the previous experiments. Twenty-four hours after injection of $2 \times 10^{7}$ t.u. (determined on BHK2 1 cells) of pHSvGN, $\sim 2 \%$ of all hepatocytes emitted green fluorescence. However, no positive hepatocytes were detected in the three animals examined at 7 days after gene transfer (Fig. 4A, B).

\section{HSV/AAV Hybrid Vector Extends Transgene Expression in Hepatocytes}

An HSV/AAV hybrid amplicon vector was previously reported to mediate extended transgene expression in cultured human glioma cells as compared with a standard HSV-1 amplicon (31). In the following experiments we analyzed (1) the capability of this hybrid vector to extend transgene expression in hepatocytes in the mouse liver, and (2) the cytotoxic and inflammatory effects associated with gene delivery. C57BL/6 mice were injected intraparenchymally with either stocks of pHyRGN (HSV/AAV hybrid amplicon that expresses $g f p$ from the cmv IEl enhancer/promoter; Fig. 1I) or vehicle alone $(10 \%$ sucrose in PBS). The transduction efficiency of this hybrid vector was as high as that of the standard amplicon vector pHSvGN in RAG2-Imice, and injection of $2 \times 10^{7}$ t.u. (determined on BHK21 cells) of pHyRGN also resulted in $\sim 2 \%$ of all hepatocytes emitting green fluorescence after $24 \mathrm{hr}$, both in injected and non- 

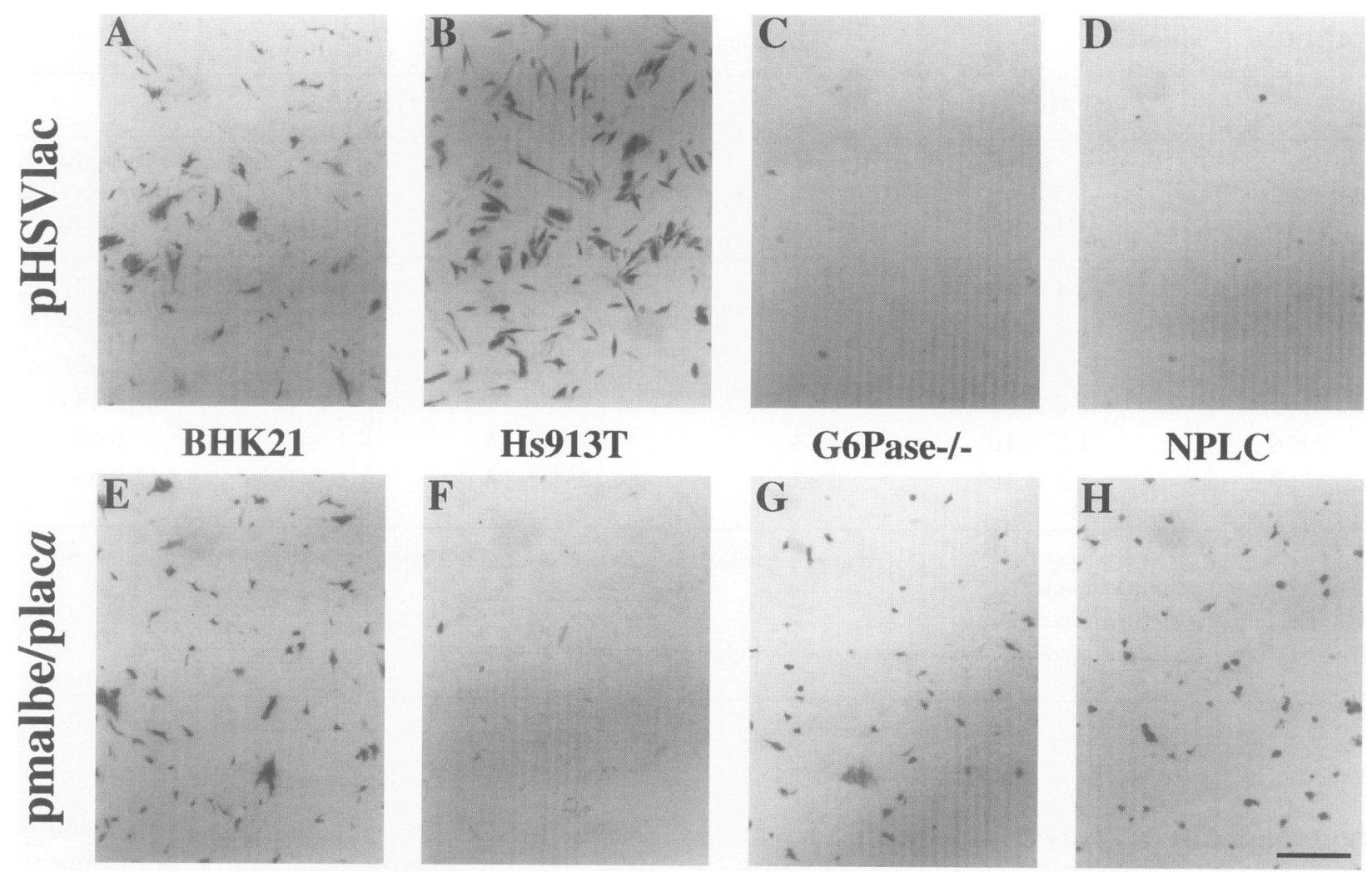

FIG. 3. Photomicrograph showing HSV-1 amplicon vector-transduced fibroblasts and hepatic cells Helper virus-free stocks $(2 \mu \mathrm{l})$ of either $(\mathrm{A}-\mathrm{D})$ pHSVlac or $(\mathrm{E}-\mathrm{H})$ pmalbe/placa were used to infect cultures of (A and E) baby hamster kidney cells (BHK21), (B and F) human lung fibroblasts (Hs913T), (C and G) G6Pase-1mouse hepatocytes, and (D and H) human hepatocytes (NPLC). Twenty-four hours after infection, cultures were stained with X-Gal. Scale bar, $200 \mu \mathrm{m}$.

injected liver lobes (Fig. 4C, D). Remarkably, however, the number of green-fluorescent hepatocytes remained constant between days 1 and 7 after gene transfer with this hybrid amplicon vector (Fig. 4E, F). Surprisingly, no green-fluorescent cells were detected in kidney or lung sections of any animal examined (not shown). Except for mild inflammatory infiltration in animals injected with either vector or vehicle alone, which was detected at day 1 and disappeared by day 7 , no differences in gross hepatocellular architecture were apparent between injected and noninjected animals (Fig. 5A-E). These findings correlated with the ALT levels (a biochemical index of hepatocyte toxicity), which at day 1 were equally elevated in the animals injected with either vector or vehicle alone and returned to normal by day 7 (Fig. 5G). Total bilirubin levels were within normal range in all animals (not shown). Fluorescent hepatocytes were still observed at 4 weeks following gene transfer with the hybrid vector, but the number of transduced cells, as well as the intensity of the fluorescence, was markedly lower than at day 1 or 7 (not shown).

\section{Readministration of Amplicon Vector}

The inefficient transduction of hepatocytes by standard adenovirus vectors upon readministration is related to the development of neutralizing antibodies to viral gene products $(6,8,10)$. Because helper virus-free HSV-l amplicon vectors express no viral genes, readministration may be more effective with this vector system. To explore this hypothesis, two mice that had been injected 4 weeks earlier with $2 \times 10^{7}$ t.u. of pHyRGN and two naive mice were intrahepatically infected with $1 \times 10^{7}$ t.u. of pHSVlac, and 1 day later, liver sections were prepared and stained with X-Gal or H\&E. In correlation with the results obtained in cultured hepatic cells (Table 1 and Fig. 3), the transduction efficiency of this vector was relatively low in hepatocytes in 

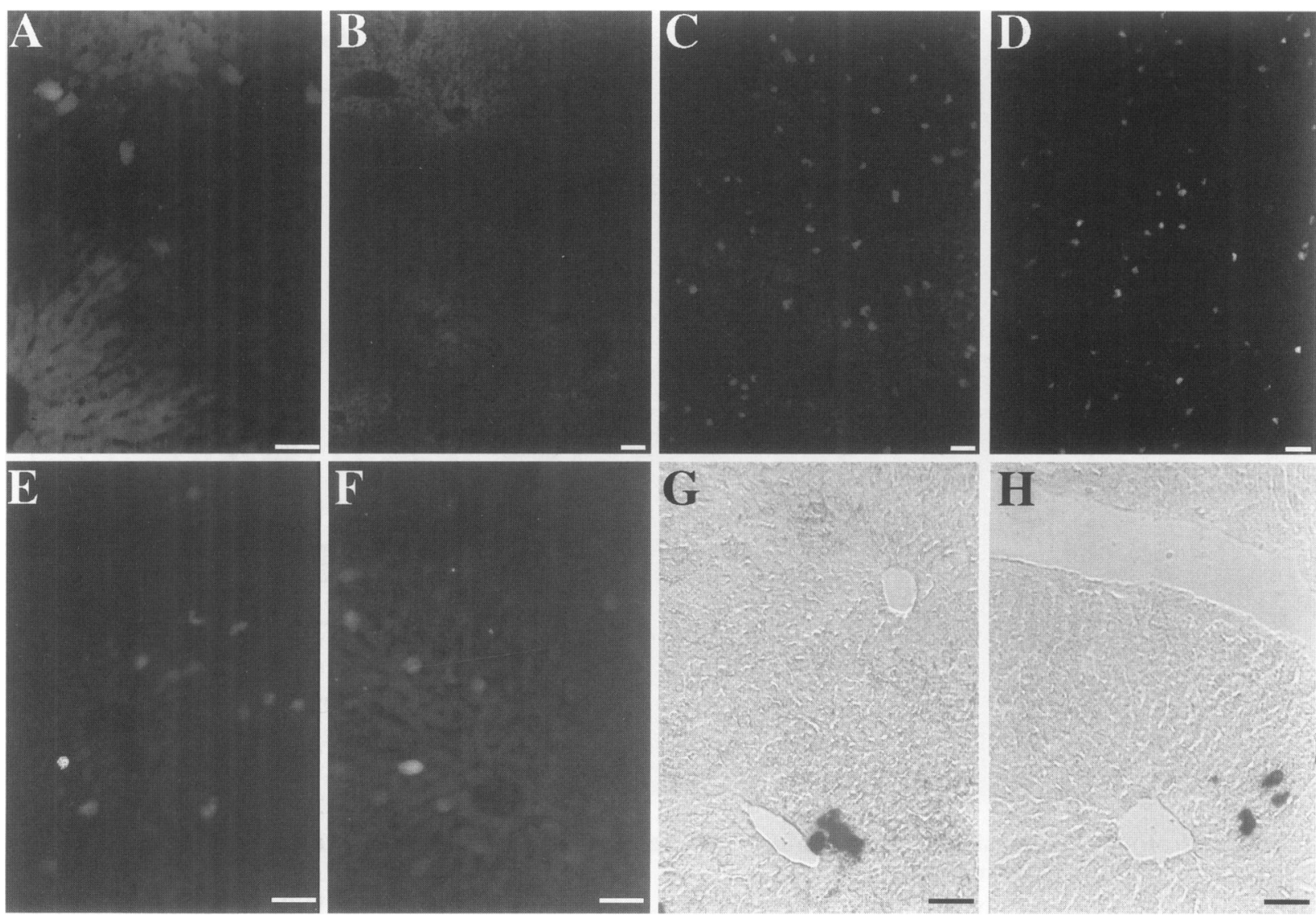

FIG. 4. HSV-1 amplicon and HSV/AAV hybrid vector-mediated gene transfer into the mouse liver Stocks (100 $\mu \mathrm{l}, 2 \times 10^{7}$ t.u.) of (A, B) pHSvGN or (C-F) pHyRGN were injected into the left liver lobe of (A, B) RAG2-1- or (C-F) normal mice (C57BL/6). Animals were killed (A, C-E) 1 day or (B, F) 7 days following gene transfer. $(G)$ Mice preinjected with pHyRGN 4 weeks earlier and $(\mathrm{H})$ naive animals were injected intraparenchymally with $1 \times 10^{7}$ t.u. $(100 \mu \mathrm{l})$ of pHSVlac and killed 1 day later. Liver sections were prepared $(20 \mu \mathrm{m})$ and (A-F) examined for green-fluorescent hepatocytes using a standard fluorescence microscope or (G and H) histochemically stained with X-Gal. Scale bars: $80 \mu \mathrm{m}(\mathrm{A}, \mathrm{B}), 100 \mu \mathrm{m}(\mathrm{C}-\mathrm{H})$.

vivo. Nevertheless, the number of transduced cells was comparable in preinjected and naive animals $(\sim 2 \beta$-galactosidase-positive cells per $\mathrm{mm}^{2}$, Fig. $\left.4 \mathrm{G}, \mathrm{H}\right)$; moreover, the second vector dose did not cause more cellular infiltration (Fig. 5F) or higher ALT levels (not shown) than the administration of a single dose of either vector or vehicle alone.

\section{DISCUSSION}

The hypothesis of this study was that the helper virus-free HSV-1 amplicon system combined with the use of liver-specific transcriptional regulatory sequences or AAV vector sequences could support both high transduction efficiencies and extended gene expression in hepatocytes in vivo. HSV-1-derived vectors have been targeted primarily to cells of the nervous system because of the neurotropism of this virus (21-23). The few experiments using HSV-1 for gene transfer into the liver have demonstrated that HSV-1 can also efficiently transduce hepatocytes (24-26). However, these studies used either recombinant HSV-1 vectors or amplicon vectors that were packaged using a helper virus, both of which induce cytotoxic effects and an immune response (27). Although gene expression from the viral promoters was transient ( $<7$ days) in these systems, a substantial number of vector genomes were still detectable even 2 months following gene transfer (24).

The helper virus-free amplicon system provides an efficient means for studying and identifying transcriptional regulatory sequences. In 

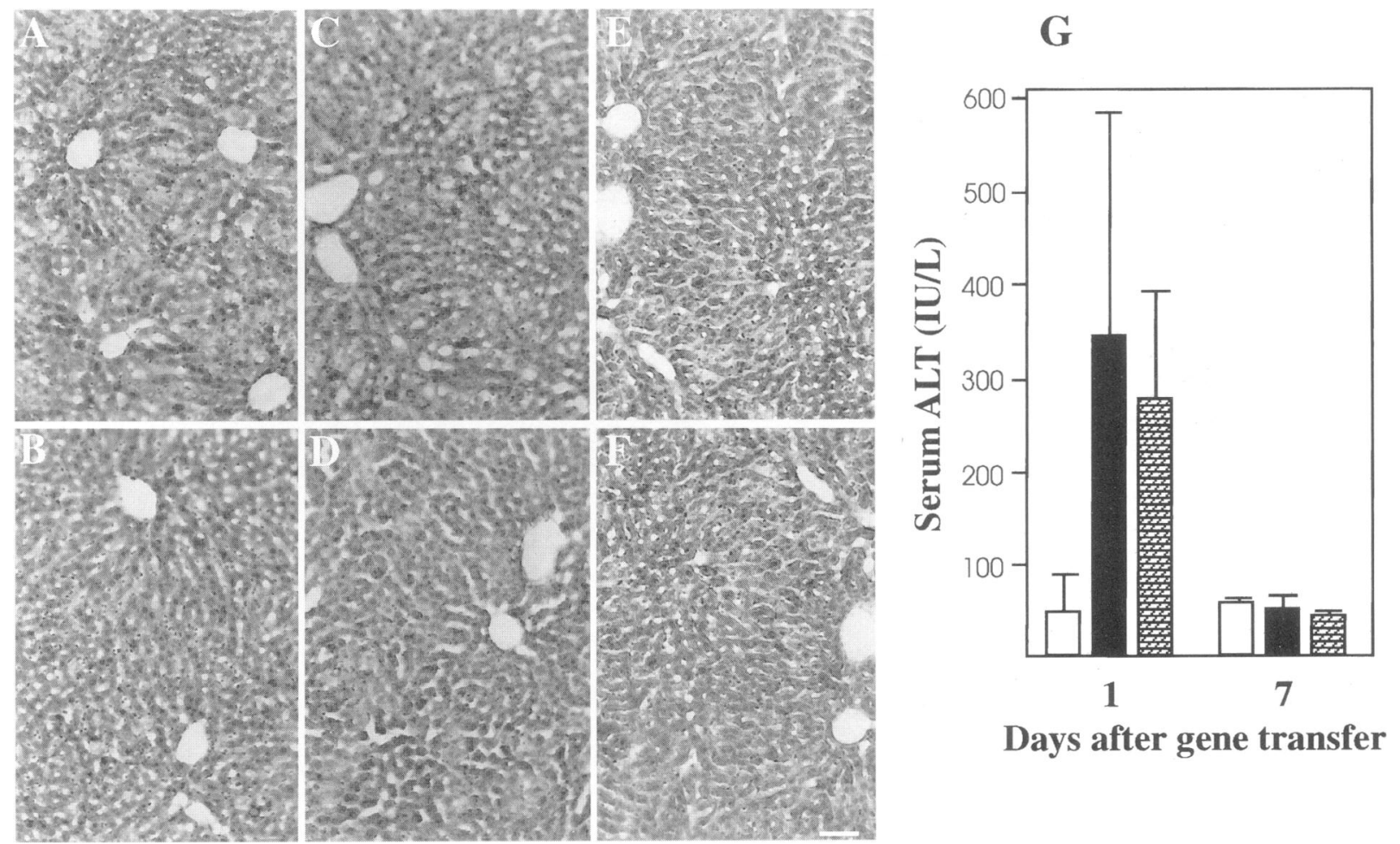

FIG. 5. Histological analysis of hepatocelluar architecture and biochemical evaluation of hepatocyte toxicity following gene transfer

C57BL/6 mice were injected with (A, C, E, F) pHyRGN as described in Figure 4 or (B) with vehicle alone (100 $\mu$ l $10 \%$ sucrose in PBS), killed after (A, B) 1, (C) 7, or (E) 28 days, and liver sections (20 $\mu$ m) were stained with H\&E. (D) Liver section from unoperated animal. (F) Mice injected with pHyRGN were super-injected 4 weeks later with $1 \times 10^{7}$ t.u. $(100 \mu \mathrm{l})$ of pHSVlac and killed after 1 day. Scale bar, $100 \mu \mathrm{m}$. (G) Blood samples collected from unoperated control mice (open bars) and from animals that were injected with either pHyRGN (closed bars) or vehicle (shaded bars) were assayed for serum transaminase (ALT) levels (IU/L). Bars indicate the mean \pm SD (vehicle, 7 days, $n=2$; all others, $n=3$ ).

our study, the titration of vector stocks on different cell lines demonstrated that the transduction efficiency (the combination of infectivity and transgene expression) of a vector can vary dramatically from cell line to cell line. This cannot be attributed exclusively to differences in cell susceptibility, as expressing the lac $Z$ reporter gene from liver-specific promoter sequences was consistently more effective (10- to 100-fold) in hepatic cells than in human lung fibroblasts, whereas the opposite was true when using the HSV-1 IE 4/5 promoter. Babiss et al. (42) have shown that transcription factors present in a variety of cells that do not express albumin can interact with the albumin promoter. This may explain why hamster kidney fibroblasts were also transduced efficiently with the vectors that contained albumin enhancer and/or promoter sequences. The hAAT promoter has been reported to be active not only in hepatocytes but also in kidney cells and neurons $(43,44)$.
Consistent with the study by Miyanohara et al. (24), administration of HSV-1 vector stock into either the portal vein or the parenchyma of one liver lobe resulted in (1) comparable transduction efficiencies; (2) an equal distribution of transduced hepatocytes in the entire organ; and (3) no transduced cells in other organs examined, including lung and kidney. Furthermore, the liver has been reported to be a primary target of adenovirus vectors, with $80 \%$ to $90 \%$ of the vector DNA found in hepatocytes after either parenchymal, portal, or peripheral tail vein infusion $(6,40)$.

Although, the efficiency of standard HSV-l amplicon vectors to transduce hepatocytes in vivo was relatively high, these vectors did not support long-term gene expression in animals; no transduced hepatocytes were observed at 7 days after gene transfer. This does not appear to be related solely to the immune response, as the same result was obtained in immunodeficient 
animals. In contrast, injection of the HSV/AAV hybrid vector into the liver of either immunodeficient (not shown) or immunocompetent mice resulted in a number of transduced cells that was comparable at 1 and 7 days after gene transfer.

The capability of this hybrid vector to extend transgene expression appears to be related to its AAV features. In AAV infections, the rep gene encodes proteins necessary for the amplification of the ITR-flanked genome; intermediates of this process include double-stranded DNA forms with terminal "hairpin" configurations that resist nuclear digestion (45). The functionality of the AAV sequences in the context of the HSV/AAV hybrid vector has been demonstrated by efficient packaging of the ITR-flanked transgene cassette into $\mathrm{AAV}$ virions in the presence of the AAV cap gene and either adenovirus or HSV-1 helper functions (31; F. Smith, personal communication). The AAV rep gene and ITRs are sufficient to direct integration of a transgene cassette into the AAVS1 site on chromosome 19 of human cells (20). Preliminary results indicate the possibility of chromosomal integration in the context of the HSV/AAV hybrid vector: efficient formation of colonies (approximately 1 colony per 16 t.u.), in which all cells were green-fluorescent, was observed 3 weeks after infection of human hepatic cells (NPLC) with pHyRGN and subsequent selection with G418 (D. R. Jacoby, unpublished data). In contrast, virtually no G418-resistant clones were obtained in control transductions with either a standard amplicon (pHSvGN) or a hybrid vector that contained the AAV ITRs but no rep gene.

In contrast to previous reports of HSV-l and adenovirus vector-mediated gene transfer into the liver, the toxicity and inflammatory effects associated with gene delivery were minimal in our study. With respect to HSV-1, this is likely due to the absence of helper virus and HSV-1 gene expression $(24,27,29,30)$. The vector caused no specific elevation in serum ALT or cellular inflammatory infiltration at 1,7 , or 28 days following gene transfer, even after readministration of vector. In contrast to standard adenovirus vectors which, because of the development of neutralizing antibodies, fail to transduce hepatoytes on readministration $(6,8,10)$, the helper virus-free amplicon vector proved equally effective in naive mice and in animals that received a first vector dose 4 weeks earlier.

In conclusion, these results demonstrate that helper virus-free HSV/AAV amplicon vectors are potentially useful vehicles for liver-directed gene transfer. The combination of advantageous features from different virus vector systems, such as the high infectibility and large transgene capacity of HSV-l and the promise for episomal amplification and human chromosomal integration of AAV may synergistically improve the prospect of future gene therapy applications. The cytomegalovirus IEl promoter used in the hybrid vector has been shown to mediate robust, albeit transient, gene expression in hepatocytes in vivo (24). In our study, reporter gene expression in hepatocytes was only occasionally detected at 4 weeks after infection with pHyRGN. We are currently exploring the use of liver-specific promoter elements in the context of this hybrid vector to further extend the efficiency of longterm gene expression.

\section{ACKNOWLEDGMENTS}

We thank Drs. K. Ponder, K. Zaret, H. Federoff, and F. Boyce for plasmid constructs, Dr. B. Knowles for the NPLC cells, Dr. F. Smith for collaborative insight, and J. Elfar for critically reading the manuscript. This work was supported by the Swiss National Science Foundation and the American Liver Foundation (C.F.), NINDS NS24279, NCI CA69246, NIDCD DC002281 (X.O.B.).

\section{REFERENCES}

1. Strauss M. (1994) Liver-directed gene therapy: prospects and problems. Gene Ther. 1: 156-164.

2. Mulligan RC. (1993) The basic science of gene therapy. Science 260: 926-932.

3. Ferry N, Duplessis O, Houssin D, Danos O, Heard JM. (1991) Retroviral-mediated gene transfer into hepatocytes in vivo. Proc. Natl. Acad. Sci. U.S.A. 88: 8377-8381.

4. Rettinger SD, Kennedy SC, Wu X, et al. (1994) Liver-directed gene therapy: Quantitative evaluation of promoter elements by using in vivo retroviral transduction. Proc. Natl. Acad. Sci. U.S.A. 91: 1460-1464.

5. Jaffe H, Danel C, Longenecker $G$, et al. (1992) Adenovirus-mediated in vivo gene transfer and expression in normal rat liver. Nat. Genet. 1: 372-378.

6. Kay MA, Landen CN, Rothenberg SA, et al. (1994) In vivo hepatic gene therapy: Complete albeit transient correction of factor IX 
deficiency in hemophilia B dogs. Proc. Natl. Acad. Sci. U.S.A. 91: 2353-2357.

7. Ohashi T, Watabe K, Uehara K, Sly WS, Vogler C, Eto Y. (1997) Adenovirus-mediated gene transfer and expression of human betaglucuronidase gene in the liver, spleen, and central nervous system in mucopolysaccharidosis type VII mice. Proc. Natl. Acad. Sci. U.S.A. 94: 1287-1292.

8. Yang Y, Wilson JM (1995) Clearance of adenovirus-infected hepatocytes by MHC class I-restricted CD4+ CTLs in vivo. J. Immunol. 155: 2564-2570.

9. Jooss K, Yang Y, Wilson JM. (1996) Cyclophosphamide diminishes inflammation and prolongs transgene expression following delivery of adenoviral vectors to mouse liver and lung. Hum. Gene Ther. 7: 1555-1566.

10. Gao GP, Yang Y, Wilson JM. (1996) Biology of adenovirus vectors with El and E4 deletions for liver-directed gene therapy. J. Virol. 70: 8934-8943.

11. Berns KI. (1996) Parvoviridae: The viruses and their replication. In: Fields BN, Knipe DM, Howley PM (eds). Virology, 3rd ed. Lippincott-Raven, Philadelphia, pp. 2173-2197.

12. Flotte TR, Afione SA, Zeitlin PL. (1994) Adeno-associated virus vector gene expression occurs in nondividing cells in the absence of vector DNA integration. Am. J. Respir. Cell Mol. Biol. 11: 517-521.

13. Russel DW, Miller AD, Alexander IE. (1994) Adeno-associated virus vectors preferentially transduce cells in $\mathrm{S}$ phase. Proc. Natl. Acad. Sci. U.S.A. 91: 8915-8919.

14. McLaughlin SK, Collis P, Hermonat PL, Muzycka N. (1988) Adeno-associated virus general transduction vectors: Analysis of proviral structures. J. Virol. 62: 1963-1973.

15. Walsh CE, Liu JM, Xiao X, Young NS, Nienhuis AW, Samulski RJ. (1992) Regulated high level expression of a human gammaglobin gene introduced into erythroid cells by an adeno-associated virus vector. Proc. Natl. Acad. Sci. U.S.A. 89: 7257-7261.

16. Linden RM, Winocour E, Berns KI. (1996) The recombination signals for adeno-associated virus site-specific integration. Proc. Natl. Acad. Sci. U.S.A. 93: 7966-7972.

17. Fisher KJ, Gao GP, Weitzman MD, DeMatteo R, Burda JF, Wilson JM. (1996) Transduction with recombinant adeno-associated virus for gene therapy is limited by leadingstrand synthesis. J. Virol. 70: 520-532.

18. Koeberl DD, Alexander IE, Halbert CL, Rus- sell DW, Miller AD. (1997) Persistent expression of human clotting factor IX from mouse liver after intravenous injection of adenoassociated virus vectors. Proc. Natl. Acad. Sci. U.S.A. 94: 1426-1431.

19. Weitzman MD, Kyöstiö SRM, Kotin RM, Owens RA. (1994) Adeno-associated virus (AAV) Rep proteins mediate complex formation between AAV DNA and its integration site in human DNA. Proc. Natl. Acad. Sci. U.S.A. 91: 5808-5812.

20. Balague C, Kalla M, Zhang WW. (1997) Adeno-associated virus Rep78 protein and terminal repeats enhance integration of DNA sequences into the cellular genome. J. Virol. 71: 3299-3306.

21. Glorioso JC, Bender MA, Goins WF, DeLuca N, Fink DJ. (1995) Herpes simplex virus as a gene-delivery vector for the central nervous system. In: Kaplitt MG, Loewy AD (eds). Viral Vectors: Gene Therapy and Neuroscience Applications. Academic Press, New York, pp. 1-23.

22. Breakefield XO, Kramm CM, Chiocca EA, Pechan PA. (1995) Herpes simplex virus vectors for tumor therapy. In: Sobol RE, Scanlon $\mathrm{KJ}$ (eds). The Internet Book of Gene Therapy: Cancer Gene Therapeutics. Appleton and Lange, Stamford, CT, pp. 41-56.

23. Fraefel C, Breakefield XO, Jacoby D. (1998) HSV-1 amplicon. In: Chiocca EA, Breakefield XO (eds). Gene Therapy for Neurological Disorders and Brain Tumors. Humana Press, Totowa, NJ, pp. 63-82.

24. Miyanohara A, Johnson PA, Elam RL, et al. (1992) Direct gene transfer to the liver with herpes simplex virus type 1 vectors: Transient production of physiologically relevant levels of circulating factor IX. New Biol. 4: 238-246.

25. Lu B, Gupta S, Federoff HJ. (1995) Ex vivo hepatic gene transfer in mouse using a defective herpes simplex virus-1 vector. Hepatology 21: 752-759.

26. Fong $Y$, Federoff HJ, Brownlee M, Blumberg D, Blumgart LH, Brennan MF. (1995) Rapid and efficient gene transfer in human hepatocytes by herpes viral vectors. Hepatology 22: 723-729.

27. Johnson PA, Yoshida K, Gage FH, Friedman T. (1992) Effects of gene transfer into cultured CNS neurons with a replication-defective herpes simplex virus type 1 vector. Mol. Brain Res. 12: 95-102.

28. Spaete RR, Frenkel N. (1982) The herpes 
simplex virus amplicon: Analyses of cis-acting replication functions. Cell 30: 295-304.

29. Fraefel C, Song S, Lim F, et al. (1996) Helper virus-free transfer of herpes simplex virus type 1 plasmid vectors into neural cells. $J$. Virol. 70: 7190-7197.

30. Aboody-Guterman KS, Pechan PA, Rainov NG, et al. (1997) Green fluorescent protein as a reporter for retrovirus and helper virusfree HSV-1 amplicon vector-mediated gene transfer into neural cells in culture and in vivo. NeuroReport (in press).

31. Johnston KM, Jacoby D, Pechan P, et al. (1997) HSV/AAV hybrid amplicon vectors extend transgene expression in human glioma cells. Hum. Gene Ther. 8: 359-370.

32. Lei K-J, Chen H, Pan C-J, et al. (1996) Glucose-6-phosphatase dependent substrate transport in the glycogen storage disease type-1a mouse. Nat. Genet. 13: 203-209.

33. Shelly LL, Lei K-J, Pan C-J, et al. (1993) Isolation of the gene for murine glucose-6phosphatase, the enzyme deficient in glycogen storage disease type 1A. J. Biol. Chem. 268: 21482-21485.

34. Pinkert CA, Ornitz DM, Brinster RL, Palmiter RD. (1987) An albumin enhancer located $10 \mathrm{~kb}$ upstream functions along with its promoter to direct efficient, liver-specific expression in transgenic mice. Genes Dev. 1: 268-276.

35. Cunningham C, Davison AJ. (1993) A cosmid-based system for constructing mutants of herpes simplex virus type 1. Virology 197: 116-124.

36. Alt FW, Rathbun G, Oltz E, Taccioli G, Shinhai Y. (1992) Function and control of recombination-activating gene activity. Ann. NY Acad. Sci. 657: 277-294.

37. Lei K-J, Shelly LL, Pan C-J, Sidbury JB, Chou JY. (1993) Mutations in the glucose- 6-phosphatase gene that cause glycogen storage disease type 1a. Science 262: $580-$ 583.

38. Folkman J, Philippart A, Tze W-J, Crigler J. (1972) Portacaval shunt for glycogen storage disease: Value of prolonged intravenous hyperalimentation before surgery. Surgery 72: 306-314.

39. Geller AI, Breakefield XO. (1988) A defective HSV-1 vector expresses Escherichia coli beta-galactosidase in cultured peripheral neurons. Science 241: 1667-1669.

40. Guo ZS, Wang LH, Eisensmith RC, Woo SLC. (1996) Evaluation of promoter strength for hepatic gene expression in vivo following adenovirus-mediated gene transfer. Gene Ther. 3: 802-810.

41. Lu B, Federoff HJ. (1995) Herpes simplex virus type 1 amplicon vectors with glucocorticoid-inducible gene expression. Hum. Gene Ther. 6: 419-428.

42. Babiss LE, Herbst RS, Bennet AL, Darnell JE. (1987) Factors that interact with the rat albumin promoter are present both in hepatocytes and other cell types. Genes Dev. 1: 256267.

43. Carlson JA, Rogers BB, Sifers RN, Hawkins HK, Finegold MJ, Woo SLC. (1988) Multiple tissues express alpha 1-antitrypsin in transgenic mice and man. J. Clin. Invest. 82: 2636.

44. Shen R-F, Clift SM, DeMayo JL, Sifers RN, Finegold MJ, Woo SLC. (1989) Tissue-specific regulation of human alpha 1-antitrypsin gene expression in transgenic mice. DNA 8: 101-108.

45. Ward P, Berns KI. (1996) In vitro replication of adeno-associated virus DNA: Enhancement by extracts from adenovirus-infected HeLa cells. J. Virol. 70: 4495-4501. 